\title{
Genotyping of CYP2D6 Polymorphisms by MALDI-TOF Mass Spectrometry in Sardinian People
}

\author{
Matteo Falzoi, ${ }^{1,2,3}$ Luigi Pira, ${ }^{1}$ Paolo Lazzari, ${ }^{1}$ and Luca Pani ${ }^{2}$ \\ ${ }^{1}$ PharmaNess S.c.a r.l., Parco Scientifico e Tecnologico della Sardegna, Edificio 5, Località Piscina Manna, 09010 Pula, Italy \\ ${ }^{2}$ Unità Operativa di Cagliari, Parco Scientifico e Tecnologico della Sardegna, Istituto di Farmacologia Traslazionale del Consiglio \\ Nazionale delle Ricerche CNR-IFT, Edificio 5, Località Piscina Manna, 09010 Pula, Italy \\ ${ }^{3}$ Dipartimento di Scienze della Vita e dell'Ambiente, Laboratori di Genetica, Università degli Studi di Cagliari, Via T. Fiorelli 1, \\ 09126 Cagliari, Italy
}

Correspondence should be addressed to Luigi Pira; luigi.pira@pharmaness.com

Received 7 March 2013; Accepted 4 April 2013

Academic Editors: B. Chen, M. A. Chiurillo, G. Giovambattista, and A. Yamamoto

Copyright (C) 2013 Matteo Falzoi et al. This is an open access article distributed under the Creative Commons Attribution License, which permits unrestricted use, distribution, and reproduction in any medium, provided the original work is properly cited.

\begin{abstract}
The CYP2D6 enzyme is involved in the metabolism of many commonly prescribed drugs. The presence of CYP2D6 gene SNPs can alter CYP2D6 enzymatic activity with effects ranging considerably within a population. Objectives. In this study, we have developed a genotyping platform able to determine the alleles related to interindividual variability in the CYP2D6 gene. Design and Methods. We used a long PCR strategy coupled to MALDI-TOF mass spectrometry (Sequenom) to develop a SNPs genotyping method. Furthermore, an amplification allele specific was carried out to infer the correct allelic phase. Results. We tested the multiplex platform in 250 DNA Sardinian samples and found it to be $100 \%$ concordant with the sequencing results of our previous work. Conclusions. The MALDI-TOF-based multiplexing system allowed simultaneous and efficient genotyping of a set of CYP2D6 SNPs, evidencing its potential use in diagnostic test development to predict drug responses and clinical outcomes.
\end{abstract}

\section{Introduction}

The presence of polymorphisms in the cytochrome $\mathrm{P} 450$ 2D6 (CYP2D6) gene may modulate enzyme levels affecting individual responses to pharmacological treatment in drug level, response, and adverse reactions and includes individuals with ultrarapid (UM), extensive (EM), intermediate (IM), and poor (PM) metabolizer status. Furthermore, the presence of multiple functional gene copies or the deletion of the entire gene results in increased or absent drug metabolism, respectively $[1,2]$. Genotypic analysis to identify individual polymorphisms has become increasingly important during drug development and for selection of individualized therapies. For this reason, high-throughput technology for rapid, accurate, and efficient genotyping is needed. Several strategies and methods for SNPs genotyping have been developed. Techniques commonly used, such as PCR-RFLP, real-time PCR, and the TaqMan allele-specific assays from Applied Biosystems (CA, USA), are often laborious, and a restricted number of alleles can be simultaneously detected by these techniques. Conversely, the high-throughput oligonucleotide microarray technology, such as the Affymetrix/Roche (CA, USA) AmpliChip CYP450 GeneChip test, has the disadvantage over other assays in that it cannot be customized by the user, and the benefits of this technology are often not compensable due to unfavourable costs [3]. In our previous work [4], we tried to create a complete genotyping platform for the simultaneous analysis of CYP $3 A 4$, CYP $3 A 5$, CYP2C9, CYP2C19, and CYP2D6 SNPs. The genotyping of the CYP2D6 gene was difficult due to its polymorphic nature, the presence of two flanking pseudogenes and copy number variants. To avoid false genotyping, resulting from nonspecific coamplification of the highly homologous pseudogenes, we developed the analysis of this gene in another way by using long PCR protocol coupled with single allele analysis and followed by sequencing [5]. In this work, we aimed to create a CYP2D6 medium-throughput SNPs screening platform using the Sequenom (CA, USA) matrix-assisted 
TABLE 1: List of 69 analyzed SNPs and correlation to aminoacid changes or transcriptional modificafications.

\begin{tabular}{|c|c|}
\hline CYP2D6 SNPs & Variations \\
\hline$-1584 C>G$ & - \\
\hline$-1426 \mathrm{C}>\mathrm{T}$ & - \\
\hline$-1235 A>G$ & - \\
\hline$-1000 \mathrm{G}>\mathrm{A}$ & - \\
\hline$-948 C>A$ & - \\
\hline$-750 \_-749$ delGA & - \\
\hline$-740 \mathrm{C}>\mathrm{T}$ & - \\
\hline$-678 \mathrm{G}>\mathrm{A}$ & - \\
\hline $19 \mathrm{G}>\mathrm{A}$ & V7M \\
\hline $31 G>A$ & V11M \\
\hline $77 \mathrm{G}>\mathrm{A}$ & $\mathrm{R} 26 \mathrm{H}$ \\
\hline $82 \mathrm{C}>\mathrm{T}$ & - \\
\hline $100 \mathrm{C}>\mathrm{T}$ & P34S \\
\hline $124 \mathrm{G}>\mathrm{A}$ & G42R \\
\hline 137_138insT & Frameshift \\
\hline $214 \mathrm{G}>\mathrm{C}\left({ }^{*}\right)$ & - \\
\hline $310 \mathrm{G}>\mathrm{T}$ & - \\
\hline $746 C>G$ & - \\
\hline $843 \mathrm{~T}>\mathrm{G}$ & - \\
\hline $883 \mathrm{G}>\mathrm{C}$ & Splicing defect \\
\hline $957 \mathrm{C}>\mathrm{T}$ & $\mathrm{A} 85 \mathrm{~V}$ \\
\hline $974 \mathrm{C}>\mathrm{A}$ & L91M \\
\hline $984 \mathrm{~A}>\mathrm{G}$ & H94R \\
\hline $997 C>G$ & - \\
\hline $1039 \mathrm{C}>\mathrm{T}$ & - \\
\hline $1513 \mathrm{C}>\mathrm{T}$ & - \\
\hline $1659 \mathrm{G}>\mathrm{A}$ & V136I \\
\hline $1661 G>C$ & - \\
\hline $1704 \mathrm{C}>\mathrm{G}$ & Q151E \\
\hline $1707 \mathrm{delT}$ & Frameshift \\
\hline $1724 \mathrm{C}>\mathrm{T}$ & - \\
\hline $1749 A>G$ & N166D \\
\hline $1757 \mathrm{C}>\mathrm{T}$ & - \\
\hline $1758 \mathrm{G}>\mathrm{A}$ & G169R \\
\hline $1758 \mathrm{G}>\mathrm{T}$ & G169X \\
\hline $1846 \mathrm{G}>\mathrm{A}$ & Splicing defect \\
\hline 1863_1864insTTTCGCCCC & 174_175insFRP \\
\hline $1869 \mathrm{~T}>\mathrm{C}$ & - \\
\hline $1943 \mathrm{G}>\mathrm{A}$ & $\mathrm{R} 201 \mathrm{H}$ \\
\hline $1979 \mathrm{~T}>\mathrm{C}$ & - \\
\hline $2291 \mathrm{G}>\mathrm{A}$ & - \\
\hline $2483 \mathrm{G}>\mathrm{T}$ & A237S \\
\hline 2539_2542delAACT & Frameshift \\
\hline 2549delA & Frameshift \\
\hline $2575 \mathrm{C}>\mathrm{A}$ & - \\
\hline 2587_2590delGACT & Frameshift \\
\hline 2615_2617delAAG & K281del \\
\hline $2850 \mathrm{C}>\mathrm{T}$ & $\mathrm{R} 296 \mathrm{C}$ \\
\hline
\end{tabular}

TABLE 1: Continued.

\begin{tabular}{lc}
\hline CYP2D6 SNPs & Variations \\
\hline $2853 \mathrm{~A}>\mathrm{C}$ & $\mathrm{I} 297 \mathrm{~L}$ \\
$2935 \mathrm{~A}>\mathrm{C}$ & $\mathrm{H} 324 \mathrm{P}$ \\
$2939 \mathrm{G}>\mathrm{A}$ & - \\
$2988 \mathrm{G}>\mathrm{A}$ & Splicing defect \\
$3176 \mathrm{C}>\mathrm{T}$ & - \\
$3183 \mathrm{G}>\mathrm{A}$ & $\mathrm{V} 338 \mathrm{M}$ \\
$3198 \mathrm{C}>\mathrm{G}$ & $\mathrm{R} 343 \mathrm{G}$ \\
$3277 \mathrm{~T}>\mathrm{C}$ & $\mathrm{I} 369 \mathrm{~T}$ \\
$3288 \mathrm{G}>\mathrm{A}$ & - \\
$3384 \mathrm{~A}>\mathrm{C}$ & - \\
$3582 \mathrm{~A}>\mathrm{G}$ & - \\
$3584 \mathrm{G}>\mathrm{A}$ & - \\
$3790 \mathrm{C}>\mathrm{T}$ & - \\
$3828 \mathrm{G}>\mathrm{A}$ & - \\
$3853 \mathrm{G}>\mathrm{A}$ & $\mathrm{E} 410 \mathrm{~K}$ \\
$3877 \mathrm{G}>\mathrm{A}$ & $\mathrm{E} 418 \mathrm{~K}$ \\
$3948 \mathrm{~T}>\mathrm{G}$ & - \\
$4115 \mathrm{C}>\mathrm{T}$ & - \\
$4155 \mathrm{C}>\mathrm{T}\left({ }^{\circ}\right)$ & $\mathrm{H} 478 \mathrm{Y}$ \\
$4180 \mathrm{G}>\mathrm{C}$ & $\mathrm{S} 486 \mathrm{~T}$ \\
$4401 \mathrm{C}>\mathrm{T}$ & - \\
$4481 \mathrm{G}>\mathrm{A}$ & - \\
\hline
\end{tabular}

In MALDI-TOF MS analysis, $\left({ }^{*}\right) 214 \mathrm{G}>\mathrm{C}$ SNP was used to discriminate gene conversion to CYP2D7P in Intron 1, and $\left({ }^{\circ}\right) 4155 \mathrm{C}>\mathrm{T}$ SNP was used to discriminate gene conversion to CYP2D7P in Exon 9. $\mathrm{A}=$ alanine; $\mathrm{R}=$ arginine; $\mathrm{N}$ = asparagine; $\mathrm{D}=$ aspartic acid; $\mathrm{C}=$ cysteine; $\mathrm{E}=$ glutamic acide; $\mathrm{Q}=$ glutamine; $\mathrm{G}$ = glycine; $\mathrm{H}=$ histidine; $\mathrm{I}=$ isoleucine; $\mathrm{L}=$ leucine; $\mathrm{K}$ = lysine; $\mathrm{M}=$ methionine; $\mathrm{F}=$ phenylalanine; $\mathrm{P}=$ proline; $\mathrm{S}=$ serine; $\mathrm{T}=$ threonine; $\mathrm{W}=$ tryptophan; $\mathrm{Y}=$ tyrosine; $\mathrm{V}=$ valine. In bold characters newly discovered SNPs in $[5,17,18,21]$.

laser desorption/ionization (MALDI) time-of-flight (TOF) mass spectrometry (MS) [6], a widely used technology that is proving to be a competitive analysis method in SNPs genotyping. Advantages of MALDI-TOF MS over previously described methods include the option for medium-highthroughput automated analysis of SNPs, the relative ease of setup for multiplex assays, and the reduced costs per genotype [3].

\section{Methods and Materials}

SNPs and Sequences Selection. The 69 polymorphisms analyzed in this study were selected using principal SNP web databases such as the Human CYP Allele Nomenclature Committee [7] and the NCBI Single Nucleotide Polymorphism dbSNP [8] websites. Selection criteria depended mainly on the pharmacogenetic effects described for every allele in the Caucasian population [5, 7, 9-16]. Not all selected SNPs are involved in aminoacidic or transcriptional variation (Table 1). Some of these are silent or promoter, leader, trailer, and intronic changes and inserted in our study because they are essential for the reconstruction of haplotype phases. The SNPs' recombination allowed the reconstruction of 66 among 
TABLE 2: List of primers used in CYP2D6 long PCR protocols. The $5^{\prime} 10$-mer tag was added to PCR primers, in order to improve PCR efficiency.

\begin{tabular}{lcccc}
\hline Nucleotides position & Name & $5^{\prime} 10$-mer tag & $5^{\prime}$-Sequence-3 & Direction \\
\hline From -1780 to -1758 & P-1780 [5] & ACGTTGGATG & GTCCTCCTGTCCTCAGTGGAT & Forward \\
From -1584 to -1559 & P-1584_WT [5] & ACGTTGGATG & CAGCCTGGACAACTTGGAAGAAGCC & Forward \\
From -1584 to -1559 & P-1584_MUT [5] & ACGTTGGATG & CAGCCTGGACAACTTGGAAGAAGCG & Forward \\
From 4706 to 4728 & 2D6-R [19] & ACGTTGGATG & ACTGAGCCCTGGGAGGTAGGTA & Reverse \\
\hline
\end{tabular}

allelic variants and subvariants. List of alleles is summarized in Table 5.

DNA Samples. In this study, we reanalyzed the genomic DNAs studied in [5]. Sardinian DNA samples were gently furnished by Professor Francesco Cucca, INN-CNR Cagliari Director. All participating individuals provided informed consent to genetic test. To genotype these samples, we implemented a CYP2D6 Genotyping Platform based on MALDI-TOF MS. This way, we would be able to compare our genotyping results with a previous sequencing analysis in [5].

\subsection{CYP2D6 Genotyping Platform}

2.1.1. Long Primary PCR. Selective amplification of the CYP2D6 gene was carried out modifying a long PCR protocol implemented in our previous work [5]. Forward primer (P1780, Table 2) was designed in a highly nonhomologous CYP2D6/CYP2D7P/CYP2D8P 5' untranslated region [5]. The reverse primer used was $2 \mathrm{D} 6-\mathrm{R}$ (Table 2 ), as previously described [19]. A $5^{\prime}$ 10-mer tag (5'-ACGTTGGATG-3') was added to both PCR primers in order to improve PCR efficiency. PCR reactions were performed in a final volume of $5 \mu \mathrm{L}$ using the QIAGEN (Hilden, Germany) LongRange PCR Kit protocol [20] with the following minor modifications: 20 ng genomic DNA, $400 \mu \mathrm{M}$ of each PCR primer (Metabion, Martinsried, Germany), 0.2 U QIAGEN LongRange PCR enzyme, 1X QIAGEN LongRange PCR buffer (containing $\mathrm{MgCl}_{2} 25 \mathrm{mM}$ ), and $500 \mu \mathrm{M}$ Invitrogen (CA, USA) $2^{\prime}$ deoxynucleoside-5' -triphosphate (dNTP) Set PCR Grade. The PCR conditions were as follows: initial denaturation at $93^{\circ} \mathrm{C}$ for $3 \mathrm{~min} ; 35$ cycles at $93^{\circ} \mathrm{C}$ for $30 \mathrm{~s}, 61^{\circ} \mathrm{C}$ for $30 \mathrm{~s}$, and $68^{\circ} \mathrm{C}$ for $6 \mathrm{~min}$.

2.1.2. SAP Dephosphorylation. To neutralize unincorporated dNTPs after amplification reactions, $0.3 \mathrm{U}$ of Shrimp Alkaline Phosphatase (SAP) (Sequenom) [26, 27] was used. SAP cleaved a phosphate from the unincorporated dNTPs, converting them to $2^{\prime}$-deoxynucleoside- $5^{\prime}$-diphosphate (dNDP) and rendering them unavailable for following reactions. Dephosphorylation conditions were as follows: $37^{\circ} \mathrm{C}$ for $20 \mathrm{~min}$ and $85^{\circ} \mathrm{C}$ for $5 \mathrm{~min}$.

2.1.3. Assay Design. SNP-specific unextended minisequencing primers (UEPs) and multiplexed UEPs assays were designed using both the Sequenom MassARRAY assay design version 3.1 and the RealSNP assay database [28]. A sequence of 400 base pairs (bp) flanking each selected SNP was downloaded from the corresponding genomic sequence stored in the public NCBI Single Nucleotide Polymorphism dbSNP database [8] or the Ensembl Genome Browser [29] and was analyzed by Vector NTI Suite Software version 5.5 (InforMax, Oxford, UK). Combination of the UEPs into multiplex assays was supported by these software applications to allow the optimization of several different parameters, for example, to avoid the risk of primer-primer interactions and hairpinloop formations, GC content, molecular mass range, and annealing temperatures. To achieve the highest possible multiplexing levels, we tested many primer combinations, leading us to the final assay design consisting in a total of 69 SNPs successfully assembled in five medium-plex assays (13-, 14-, 13-, 14-, and 15-plex) (Table 3). For some SNPs, Sequenom MassARRAY assay design and RealSNP assay database could not design SNP-specific UEPs because of the presence of proximal SNPs. Other SNPs were excluded during platform validation because of UEPs cross-hybridization in highly homologous PCR template regions or for the presence of primer dimers which created false allele. But the high number of SNPs inserted in our analysis has allowed us to infer the correct alleles for each DNA analysis. List of SNPs not included is summarized in Table 4.

2.1.4. iPLEX Reactions. iPLEX reactions were carried out following the Sequenom standard low/medium-plex protocol $[6,26,27]$, with minor modifications. Because of the length of the primary PCR fragment and the high GC content, we increased the denaturation time at $94^{\circ} \mathrm{C}$ from 5 to $30 \mathrm{sec}$ and the annealing temperature from 52 to $56^{\circ} \mathrm{C}$. An iPLEX reaction cocktail was added to the amplification products and thermocycled to process the iPLEX reaction, which involved the enzymatic addition of one of the four mass-modified nucleotides, $2^{\prime}, 3^{\prime}$-dideoxynucleoside- $5^{\prime}$ triphosphate (ddNTP), into the polymorphic site. During the iPLEX reaction, each primer was extended by one of the ddNTPs which terminated the extension of primers, thus producing allele-specific extension products of different masses. The iPLEX reaction cocktail included 0.222X iPLEX buffer plus, 0.5X iPLEX termination mix, 0.5X iPLEX enzyme, and UEPs, which were divided into four mass groups, according to the position of their respective mass peaks to use the whole spectrum (final concentrations of $0.8-2.0 \mu \mathrm{M}$ ). In the iPLEX termination mix, all four ddNTPs are present at the same concentration. The reactions were performed using a two cycling loop program: initial denaturation at $94^{\circ} \mathrm{C}$ for $30 \mathrm{~s}$; followed by 40 cycles of $94^{\circ} \mathrm{C}$ for $30 \mathrm{~s}, 56^{\circ} \mathrm{C}$ for $5 \mathrm{~s}$, and $80^{\circ} \mathrm{C}$ for $5 \mathrm{~s}$. This annealing and extension procedure was repeated four times (to give a total of 200 short cycles), followed by a final extension step of $3 \mathrm{~min}$ at $72^{\circ} \mathrm{C}$. After desalting 


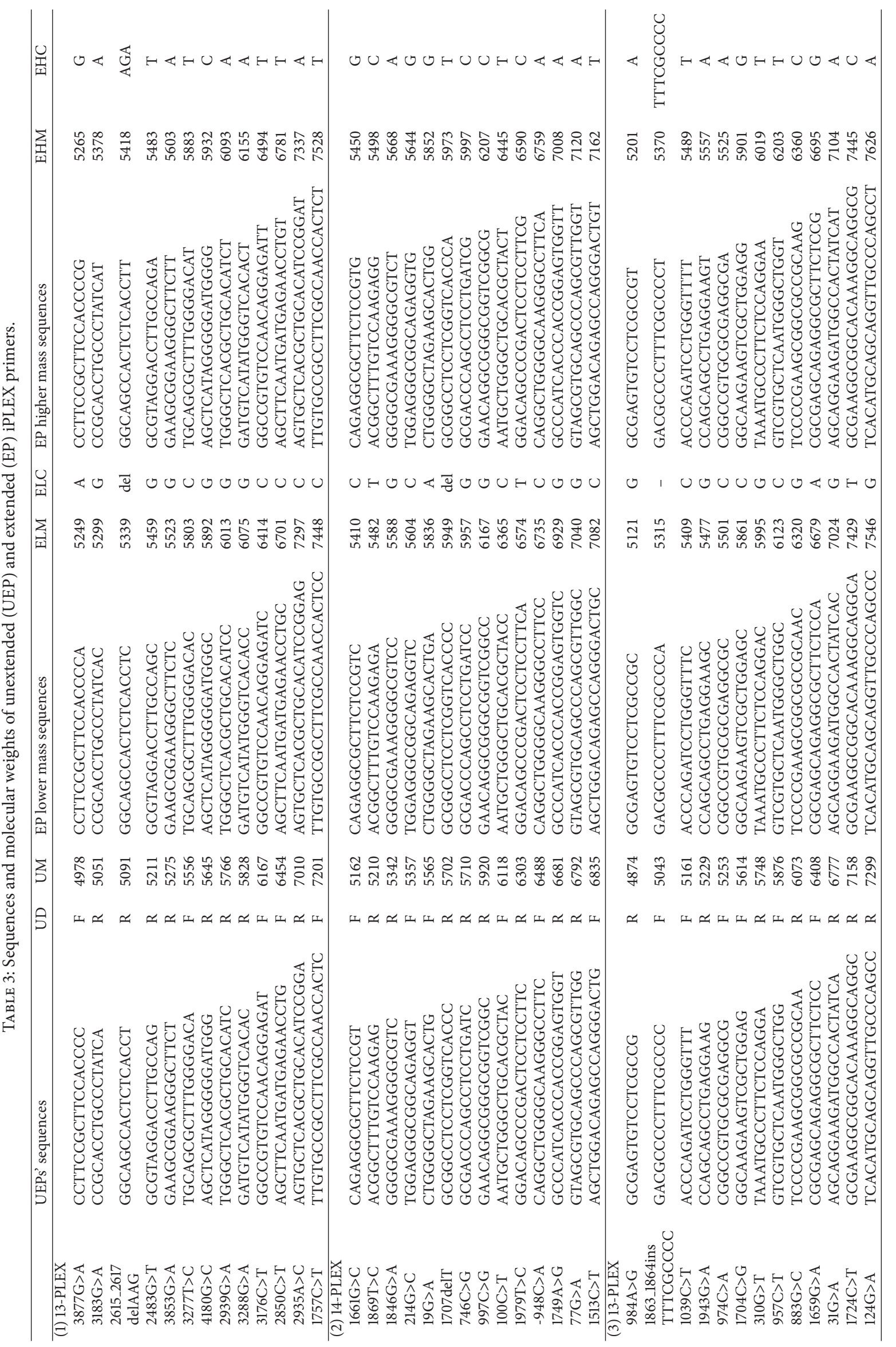




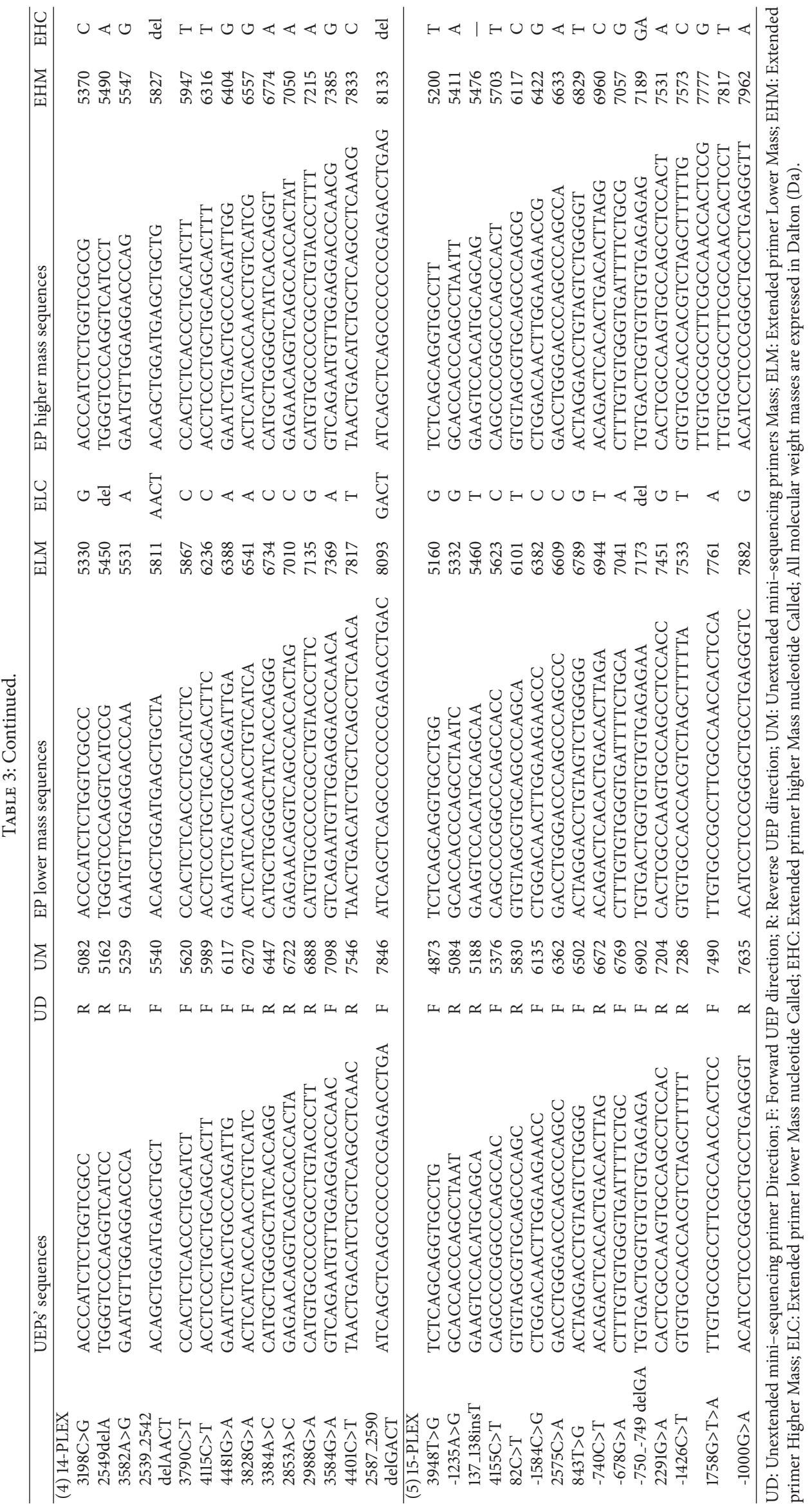


TABLE 4: List of SNPs excluded in assay design validation and correlation to transcriptional variations.

\begin{tabular}{lcc}
\hline SNPs excluded & Variations & Reason \\
\hline$-1770 \mathrm{G}>\mathrm{A}$ & - & Cross-hybridization \\
$-1298 \mathrm{G}>\mathrm{A}$ & - & Primer dimers \\
$-1253 \mathrm{~A}>\mathrm{G}$ & - & Primer dimers \\
-1237_-1236insAA & - & $\begin{array}{c}\text { Proximal SNP -1235A }>\mathrm{G} \\
\text { Primer dimers }\end{array}$ \\
1973_1974insG & Frameshift & Proximal SNP 1979T $>\mathrm{C}$ \\
1976G $>$ A & - & Proximal SNP 1979T $>\mathrm{C}$ \\
1978C $>\mathrm{T}$ & - & Proximal SNP 1979T $>\mathrm{C}$ \\
2097A $>\mathrm{G}$ & - & Primer dimers \\
2470T $>$ C & - & Cross hybridization \\
4042G $>$ A & - & Primer dimers \\
\hline
\end{tabular}

by addition of $6 \mathrm{mg}$ clean resin (Sequenom), each 384-well sample was diluted with $16 \mu \mathrm{L}$ of sterilized $\mathrm{H}_{2} \mathrm{O}_{\mathrm{dd}}$.

Multiplex PCR reactions, SAP dephosphorylation, and iPLEX reactions were performed using Thermo-Fast 384 PCR Plates (ABgene, Epsom, UK) and a DNA Engine Tetrad 2 Peltier Thermal Cycler (Bio-Rad, CA, USA). All pipetting steps were performed using the automatic station Matrix PlateMate $2 \times 2$ (Sequenom).

2.1.5. MALDI-TOF MS Measurement. An aliquot ranging from 15 to $20 \mathrm{~nL}$ of each iPLEX reaction product was loaded in a 384-spot SpectroChip (Sequenom) using the MassArray Nanodispenser (Samsung, Seoul, Repubic of Korea). SpectroChip analysis was performed by MassARRAY Compact System (Sequenom). After laser desorption/ionization, automated spectra acquisition analysis was performed and interpreted using Sequenom MassARRAY RT version 3.3 software. Examples of multiplex mass spectrum and cluster plot distributions are shown in Figures 1 and 2.

2.2. CYP2D6 Single Allele Genotyping. Following direction of our previous work [5], we decided to apply the single allele protocol creating a single allele genotyping method MALDI-TOF MS based. For each sample, a double long PCR reaction was carried out using P-1584_WT or P-1584_MUT [5] (Table 2) as forward primers. The reverse primer was 2D6-R [19] for both PCR reactions. In this way, we were able to directly determine a direct and correct chromosome phase in samples presenting with a heterozygous status for $-1584 \mathrm{G}>\mathrm{C}$ SNP. PCR reactions were performed in a final volume of $5 \mu \mathrm{L}$ using $20 \mathrm{ng}$ genomic DNA, $400 \mu \mathrm{M}$ of each PCR primer (Metabion), 0.2 U QIAGEN LongRange PCR enzyme, 1X QIAGEN LongRange PCR buffer (containing $\mathrm{MgCl}_{2} 25 \mathrm{mM}$ ), and $800 \mu \mathrm{M}$ Invitrogen dNTP set PCR grade. The PCR conditions were as follows: initial denaturation at $93^{\circ} \mathrm{C}$ for $3 \mathrm{~min} ; 10$ cycles at $93^{\circ} \mathrm{C}$ for $30 \mathrm{~s}, 67^{\circ} \mathrm{C}$ for $30 \mathrm{~s}$, and $68^{\circ} \mathrm{C}$ for $3 \mathrm{~min} ; 25$ cycles at $93^{\circ} \mathrm{C}$ for $30 \mathrm{~s}, 65^{\circ} \mathrm{C}$ for $30 \mathrm{~s}$, and $68^{\circ} \mathrm{C}$ for $6 \mathrm{~min}$. SAP dephosphorylation, iPLEX Reactions and MALDI-TOF MS measurement were performed without
TABLE 5: CYP2D6 allele frequencies in 250 healthy Sardinian people. Total chromosomes number $=500$. Human cytochrome P450 Allele Nomenclature Committee [7] served as reference for variant allele and correlated enzymatic activity.

\begin{tabular}{|c|c|c|c|}
\hline Variant allele & $\begin{array}{l}\text { Number of } \\
\text { chromosomes }\end{array}$ & $\begin{array}{l}\text { Frequency } \\
(\%)\end{array}$ & $\begin{array}{c}\text { Correlated } \\
\text { enzymatic activity }\end{array}$ \\
\hline${ }^{*} 1 A$ & 148 & 29.6 & EM \\
\hline${ }^{*} 1 B$ & 5 & 1.0 & EM \\
\hline${ }^{*} 1 D$ & 4 & 0.8 & EM \\
\hline${ }^{*} 1 E$ & - & - & EM \\
\hline${ }^{*} 2 A$ & 75 & 15.0 & EM \\
\hline${ }^{*} 2 B$ & - & - & EM \\
\hline${ }^{*} 2 \mathrm{D}$ & - & - & EM \\
\hline${ }^{*} 2 E$ & - & - & EM \\
\hline${ }^{*} 2 F$ & - & - & EM \\
\hline${ }^{*} 2 G$ & - & - & EM \\
\hline${ }^{*} 2 K$ & - & - & EM \\
\hline${ }^{*} 2 L$ & 11 & 2.2 & EM \\
\hline${ }^{*} 2 M$ & 8 & 1.6 & EM \\
\hline $\mathrm{SH} 3$ & 7 & 1.4 & Not known \\
\hline SH4 & 1 & 0.2 & Not known \\
\hline${ }^{*} 3 A$ & - & - & $\mathrm{PM}$ \\
\hline${ }^{*} 3 B$ & 11 & 2.2 & $\mathrm{PM}$ \\
\hline${ }^{*} 4 A$ & 84 & 16.8 & $\mathrm{PM}$ \\
\hline${ }^{*} 4 B$ & - & - & $\mathrm{PM}$ \\
\hline$* 4 D$ & - & - & $\mathrm{PM}$ \\
\hline${ }^{*} 4 K$ & - & - & $\mathrm{PM}$ \\
\hline${ }^{*} 4 L$ & - & - & $\mathrm{PM}$ \\
\hline${ }^{*} 4 M$ & - & - & $\mathrm{PM}$ \\
\hline${ }^{*} 4 \mathrm{~N}$ & - & - & $\mathrm{PM}$ \\
\hline$* 5$ & 5 & 1.0 & $\mathrm{PM}$ \\
\hline${ }^{*} 6 A$ & 1 & 0.2 & $\mathrm{PM}$ \\
\hline${ }^{*} 6 C$ & - & - & $\mathrm{PM}$ \\
\hline$* 6 D$ & - & - & $\mathrm{PM}$ \\
\hline$* 7$ & - & - & $\mathrm{PM}$ \\
\hline$* 8$ & - & - & $\mathrm{PM}$ \\
\hline${ }^{*} 9$ & 1 & 0.2 & IM \\
\hline${ }^{*} 10 \mathrm{~A}$ & - & - & IM \\
\hline${ }^{*} 10 B$ & 27 & 5.4 & IM \\
\hline${ }^{*} 11$ & - & - & $\mathrm{PM}$ \\
\hline${ }^{*} 12$ & - & - & $\mathrm{PM}$ \\
\hline${ }^{*} 14 A$ & - & - & $\mathrm{PM}$ \\
\hline${ }^{*} 14 B$ & - & - & IM \\
\hline${ }^{*} 15$ & 3 & 0.6 & $\mathrm{PM}$ \\
\hline${ }^{*} 17$ & - & - & IM \\
\hline$* 19$ & - & - & $\mathrm{PM}$ \\
\hline$* 20$ & 1 & 0.2 & $\mathrm{PM}$ \\
\hline${ }^{*} 22$ & - & - & Not known \\
\hline${ }^{*} 23$ & - & - & Not known \\
\hline
\end{tabular}


TABLE 5: Continued.

\begin{tabular}{|c|c|c|c|}
\hline Variant allele & $\begin{array}{l}\text { Number of } \\
\text { chromosomes }\end{array}$ & $\begin{array}{l}\text { Frequency } \\
(\%)\end{array}$ & $\begin{array}{c}\text { Correlated } \\
\text { enzymatic activity }\end{array}$ \\
\hline${ }^{*} 24$ & - & - & Not known \\
\hline *25 & - & - & Not known \\
\hline${ }^{*} 26$ & - & - & Not known \\
\hline${ }^{*} 27$ & - & - & EM \\
\hline${ }^{*} 28$ & 4 & 0.8 & Not known \\
\hline * 29 & - & - & IM \\
\hline *30 & - & - & Not known \\
\hline${ }^{*} 31$ & - & - & $\mathrm{PM}$ \\
\hline${ }^{*} 32$ & - & - & Not known \\
\hline${ }^{*} 33$ & - & - & EM \\
\hline *35A & 5 & 1.0 & EM \\
\hline${ }^{*} 36$ & - & - & IM \\
\hline${ }^{*} 37$ & - & - & Not known \\
\hline *38 & - & - & PM \\
\hline *39 & - & - & EM \\
\hline$* 41$ & 46 & 9.2 & IM \\
\hline SH1 & 41 & 8.2 & Not known \\
\hline $\mathrm{SH} 2$ & 2 & 0.4 & Not known \\
\hline${ }^{*} 43$ & - & - & Not known \\
\hline *58 & - & - & Not known \\
\hline *59 & - & - & IM \\
\hline *64 & - & - & Not known \\
\hline *65 & - & - & Not known \\
\hline${ }^{*} 1 x N$ & 4 & 0.8 & UM \\
\hline$* 2 x N$ & 6 & 1.2 & UM \\
\hline
\end{tabular}

SH1,2,3,4 = Sardinian haplotype 1,2,3,4 [5, 22-25]. CYP2D6 ${ }^{*} 5,{ }^{*} 1 x N$; and ${ }^{*} 2 x N$ alleles were evaluated by The CYP2D6 Applied Biosystems CNV Assay in [5].

modifications as indicated in paragraph 1 "CYP2D6 Genotyping Platform". In multiplexed assay 5, $-1584 \mathrm{G}>\mathrm{C}$ UEP (Table 3) was excluded. Examples of cluster distribution for novel $3176 \mathrm{C}>\mathrm{T}$ and $3948 \mathrm{~T}>\mathrm{G}$ SNPs $[5,17,18]$ are shown in Figure 3.

\section{Results and Discussion}

A CYP2D6 screening assay was developed using the Sequenom MassARRAY platform to simultaneously identify the most frequent and some rare CYP2D6 Caucasian alleles. We have modified the basic Sequenom iPLEX assay and used a new primary PCR strategy based on the amplification of the entire gene [5] coupled with multiplex primer extension reactions. This strategy avoids false genotyping, which would result in nonspecific coamplification of the homologous pseudogenes CYP2D7P and CYP2D8P, and, secondly, it reduces the number of PCR primers used to select regions containing the targeted polymorphisms. Multiplexing was performed for 69 SNPs, which represents 66 of the most frequent and some rarer variants and subvariants reported

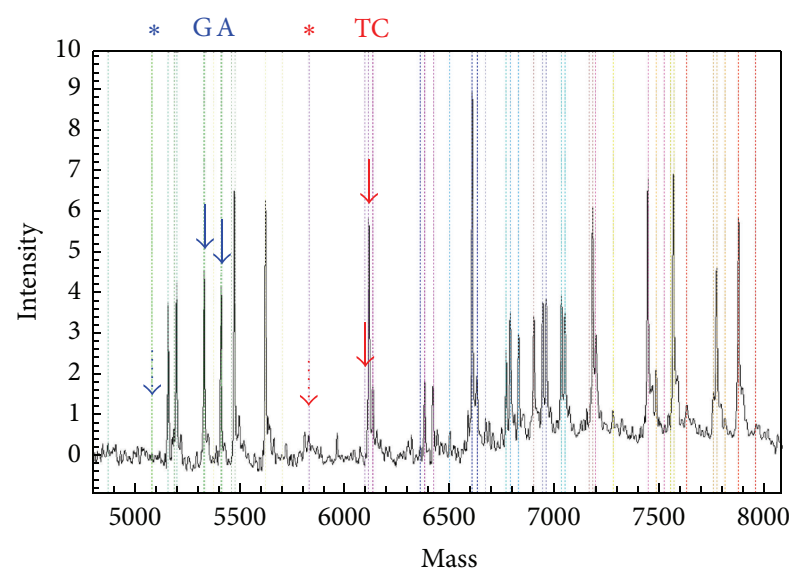

Figure 1: An example of 15-plex mass spectrum is shown (Well 5). List of SNPs investigated in this plex is shown in Table 3. The figure shows two examples highlighted in different colours. Unextend primer (UEP) peak is marked by an asterisk and dotted arrow, while the solid arrows indicate the presence of the two different alleles. Dotted vertical lines represent UEPs and extended primers (EPs) expected masses. In blue, an AG heterozygous genotype example is shown. * : $-1235 \mathrm{~A}>\mathrm{G}$ UEP; expected mass $=5084$ Dalton (Da). G: $-1235 \mathrm{~A}>\mathrm{G}$ EP; expected mass $=5332 \mathrm{Da}$. A: $-1235 \mathrm{~A}>\mathrm{G}$ EP; expected mass $=5411 \mathrm{Da}$. In red, a CC wild type homozygous genotype example is shown. ${ }^{*}: 82 \mathrm{C}>\mathrm{T}$ UEP; expected mass $=5830 \mathrm{Da}$. T: $82 \mathrm{C}>\mathrm{T}$ not EP; expected mass $=6101 \mathrm{Da} . \mathrm{C}: 82 \mathrm{C}>\mathrm{T}$ EP; expected mass $=6117 \mathrm{Da}$

to date in the Caucasian population $[5,7,9-16]$ and known to be responsible for absent, reduced or extensive metabolic activity (Tables 1 and 5). Due to the high possibility of recombination, it was possible to insert African, AfricanAmerican $\left(C Y P 2 D 6^{*} 2 L,{ }^{*} 2 M,{ }^{*} 4 N,{ }^{*} 64\right.$, and $\left.{ }^{*} 65\right)$ and Asian $\left(C Y P 2 D 6^{*} 3 A,{ }^{*} 4 B,{ }^{*} 4 L,{ }^{*} 14,{ }^{*} 36\right.$, and $\left.{ }^{*} 39\right)$ variants in the study. A sample of 250 unrelated healthy Sardinian individuals analyzed in [5] was submitted to MALDI-TOF MS genotyping for these 69 CYP2D6 SNPs. An example of multiplex mass spectrum is shown in Figure 1. In Figure 2(a), an example of the cluster plot distribution for the $1661 \mathrm{G}>\mathrm{C}$ SNP is shown. Spectrum peak intensities were not correctly balanced in some heterozygous samples (Figures 2(c) and $2(\mathrm{~d})$ ), which appeared as outliers in the cluster distribution (Figure 2(a) point $\delta$ and $\varepsilon$ ). The CYP2D6 Applied Biosystems Copy Number Variation (CNV) Assay used to analyze these DNAs in our previous work [5] detected the presence of duplications or multiplications in $100 \%$ of the analyzed samples presenting this kind of distribution. Furthermore, in samples presenting a heterozygous status for $-1584 \mathrm{G}>\mathrm{C}$ SNP, we applied long PCR single allele analysis [5] to MALDITOF MS screening assays and inferred a direct haplotype phase. To verify if our CYP2D6 platform works correctly, we compared genotyping results and haplotype phase elaborated in the two screening platforms with our results found in [5]. A consensus of $100 \%$ was found for all samples (Table 5). Moreover, for all samples presenting the $214 \mathrm{G}>\mathrm{C}$ SNP in homo- or heterozygous status in MALDI-TOF MS analysis, it was possible to verify in our previous sequencing analysis 


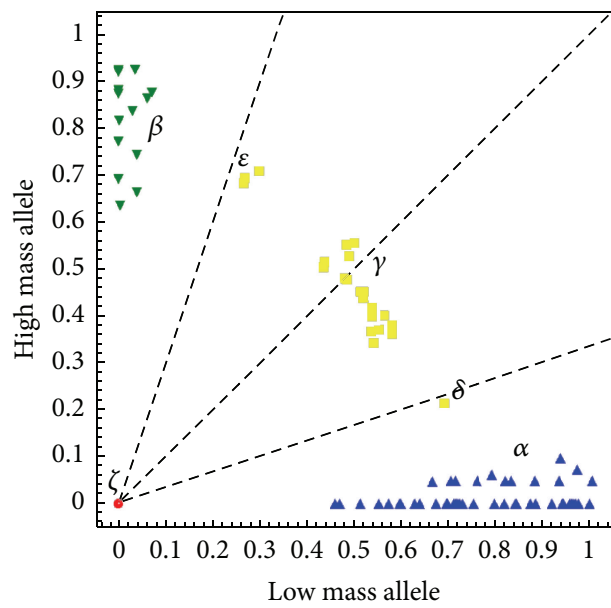

(a)

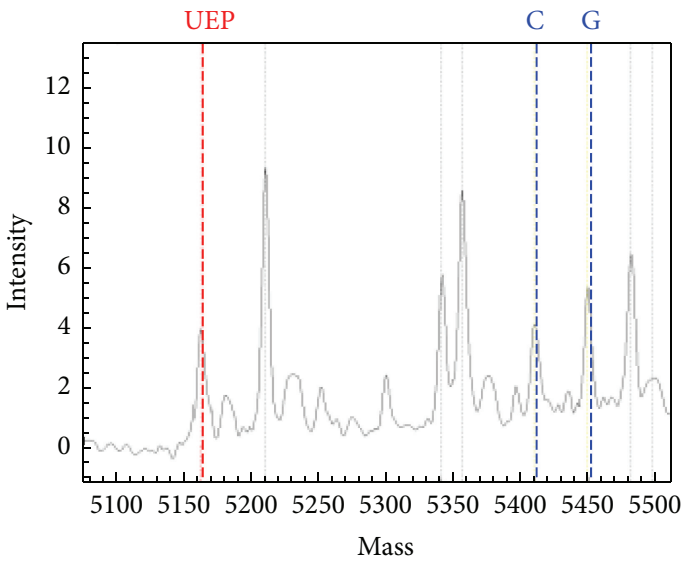

(c)

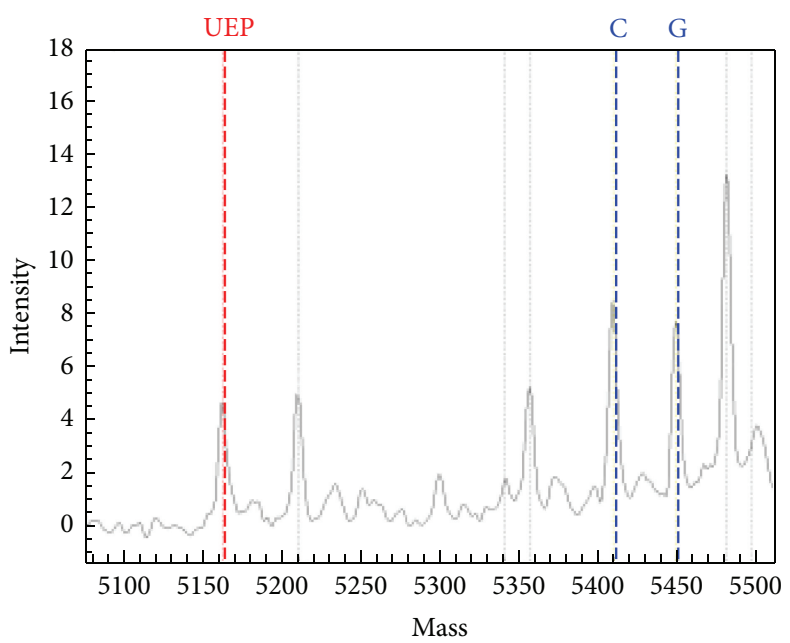

(b)

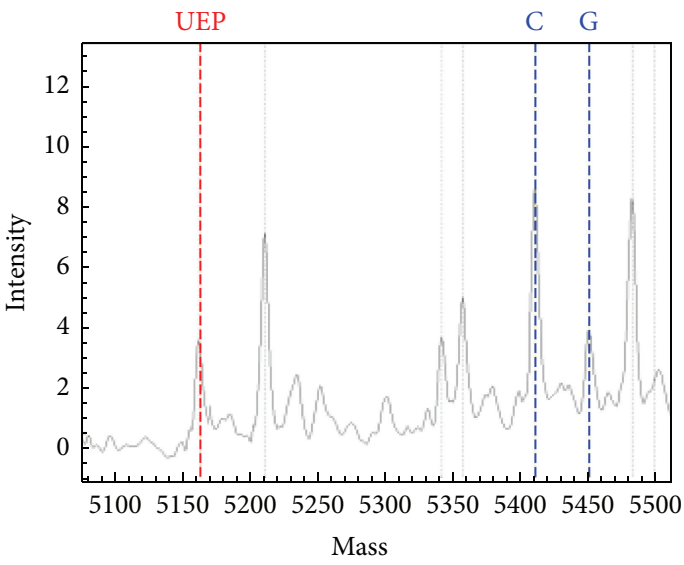

(d)

FIGURE 2: In (a) a Cluster plot for 1661G >C SNP is shown. Homozygous wild type G/G samples are displayed in $(\alpha)$, homozygous mutate C/C samples in $(\beta)$ and heterozygous $\mathrm{G} / \mathrm{C}$ samples in $(\gamma)$; in $(\delta)$ and $(\varepsilon)$ are displayed outlier samples resulting in gene copy number variation [5]; $(\zeta)$ negative control (H2Odd). In (b) a Mass Spectra for the detection of $1661 \mathrm{G}>\mathrm{C}$ in a heterozygous G/C sample, displayed in (a) position $(\gamma)$. In (c) a Mass Spectra for the detection of $1661 \mathrm{G}>\mathrm{C}$ in the outlier sample, displayed in (a) position $(\delta)$, and resulting in $C Y P 2 D 6^{*} 1 \times N$ allele [5]. In (d) Mass Spectra for the detection of $1661 \mathrm{G}>\mathrm{C}$ in an outlier sample, displayed in (a) position $(\varepsilon)$, and resulting in $C Y P 2 D 6^{*} 2 \times N$ allele [5].

[5] the presence of all SNPs correlated to gene conversion to $C Y P 2 D 7 P$ in Intron 1 (Figure 4), which indicated the reliability of MALDI-TOF analysis for this variation.

\section{Conclusions}

Differences in drug responses could be due to genetic factors. Knowledge of individual genetic profiling is clinically important and provides benefits for future medical care by predicting the drug response or developing DNA-based tests. Substantial interindividual variability in response to specific therapies might be caused by the presence of polymorphisms in genes encoding components of drug metabolism pathways, such as the CYP450 family genes. Polymorphisms in CYP2D6 gene have been thoroughly investigated, including their associations with the incidence of adverse reactions. In this study, we have developed a reliable medium-throughput genotyping platform using the Sequenom MassARRAY system to provide a simultaneous screening of the most relevant CYP2D6 gene variants in several hundreds of subjects. MALDI-TOF MSbased analyses have the potential to become a useful approach in clinical diagnoses, as they are very flexible and applicable to individualized genetic therapies. The screening platform developed in this study, coupled with The CYP2D6 Applied Biosystems CNV Assay, provides a robust alternative to many currently available CYP450-genotyping approaches and aims to increase the number of responders and to limit the incidences of adverse events. Moreover, by modifying long PCR Forward primer, we have implemented a rapid strategy to infer the phase by direct analysis using MALDI-TOS MS multiplex assays. Concordance between data found in this work and our direct genomic DNA sequencing analysis done in [5] reliably validated our MALDI-TOF MS-based platform. 


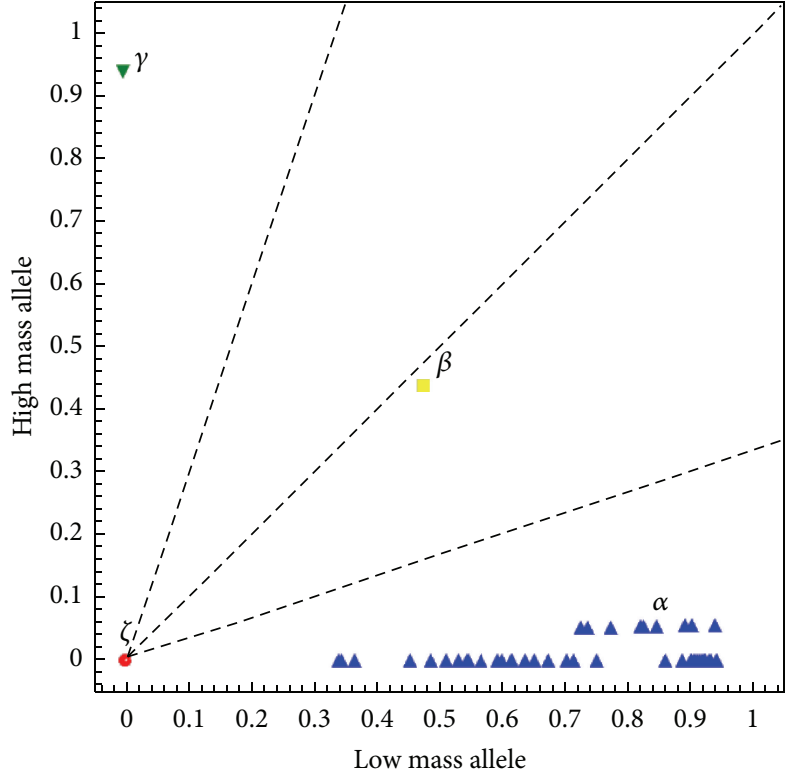

(a)

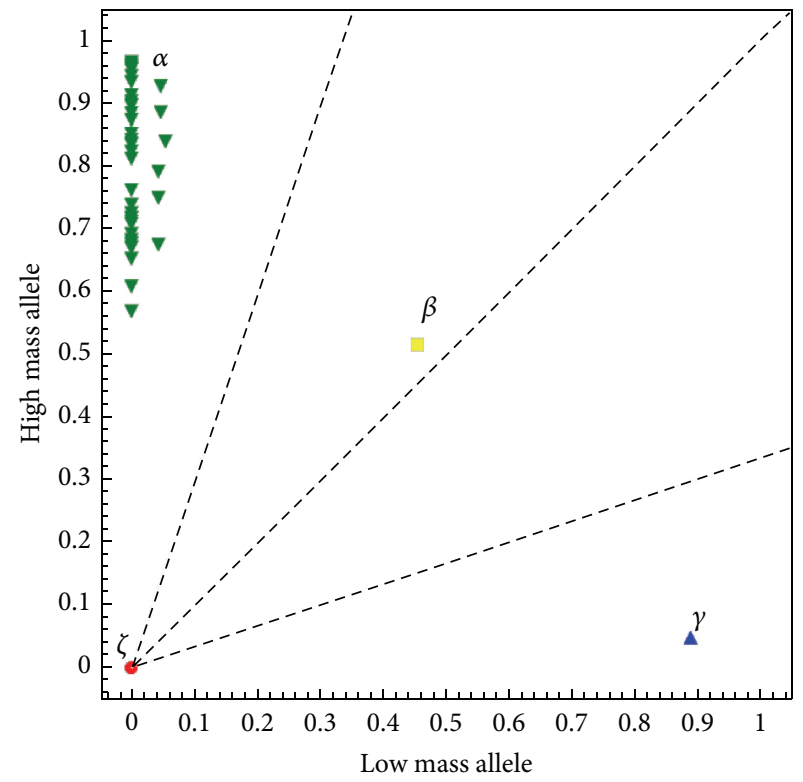

(b)

FIGURE 3: MALDI-TOF MS cluster plot distribution for 3176C $>\mathrm{T}$ [17] and 3948G $>\mathrm{T}$ [18] newly discovered SNPs [5]. In each cluster, there are visualized 32 samples presenting heterozygous status for $-1584 \mathrm{G}>\mathrm{C}$ SNP and submitted to both types of PCR analysis, LongRange PCR (Section 2, paragraph 1) and the two single allele PCR (Section 2, paragraph 2), for a total of 96 PCR analyses. (a) Cluster plot for 3176C>T SNP. $(\alpha)$ homozygous wild type $\mathrm{C} / \mathrm{C}$ samples; $(\beta)$ one out of the two heterozygous $\mathrm{C} / \mathrm{T}$ samples presenting heterozygous status for $-1584 \mathrm{G}>\mathrm{C}$ SNP also; $(\gamma)$ the same heterozygous sample analysed in single allele PCR; $(\zeta)$ negative control $\left(\mathrm{H}_{2} \mathrm{O}_{\mathrm{dd}}\right)$. (b) Cluster plot for $3948 \mathrm{~T}>\mathrm{G}$ SNP. $(\alpha)$ homozygous wild type T/T samples; $(\beta)$ the only heterozygous T/G sample; $(\gamma)$ the only heterozygous sample analysed in single allele PCR; $(\zeta)$ negative control $\left(\mathrm{H}_{2} \mathrm{O}_{\mathrm{dd}}\right)$.

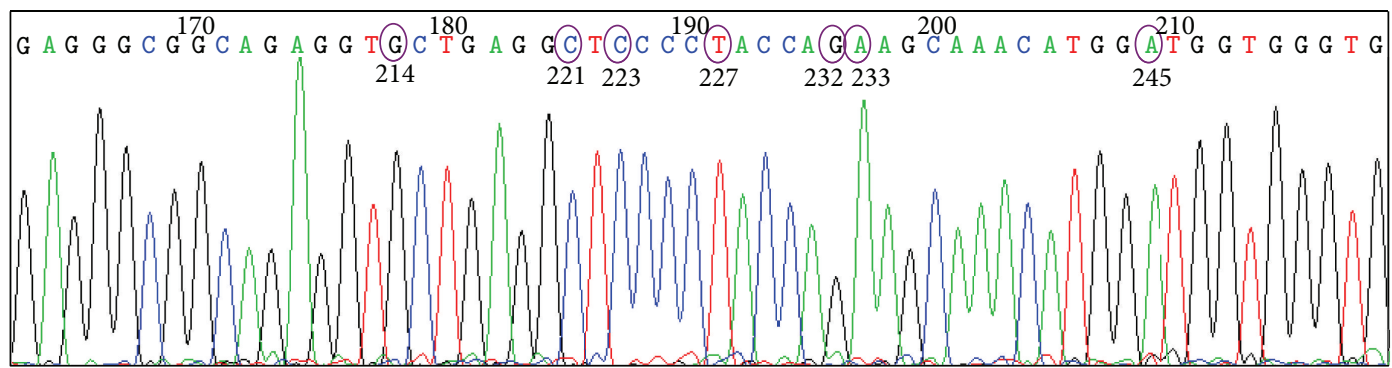

(a)

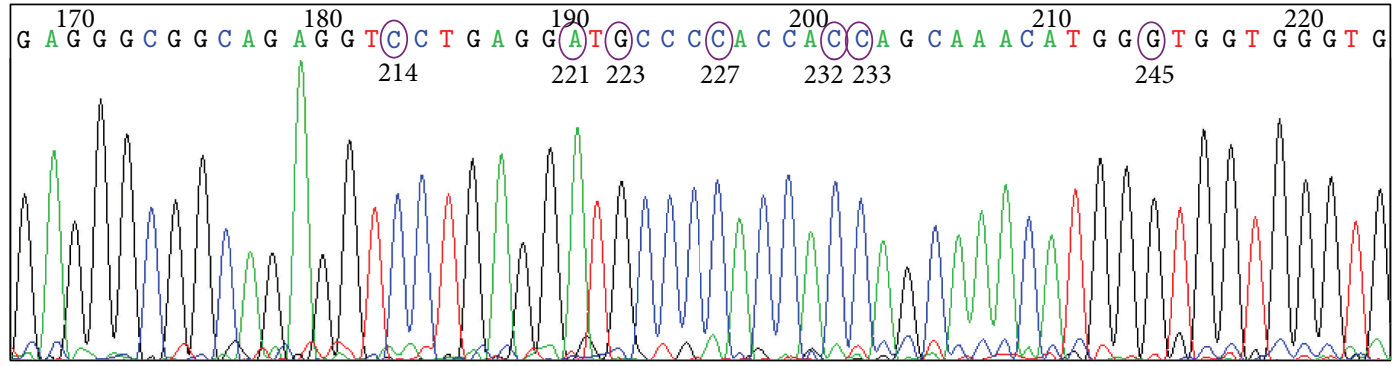

(b)

FIGURE 4: (a) Electropherograms of a homozygous wild type and (b) a homozygous mutate sample for CYP2D6/CYP2D7P gene conversion in Intron 1 analyzed in [5]. SNPs are circled in purple; reference positions are indicated under each SNP. For all samples presenting 214G>C SNP in homo- or heterozygous status in MALDI-TOF MS analysis, it was confirmed the presence of all SNPs correlated to gene conversion in Intron 1 by sequencing analysis. 


\section{Conflict of Interests}

The authors declare not to have a financial relation with the commercial identities mentioned in the paper that might lead to a conflict of interests.

\section{Acknowledgments}

The authors gratefully acknowledge Professor Francesco Cucca, INN-CNR Cagliari Director, for gently furnishing Sardinian DNAs; Dr. Luisella Saba and Dr. Elena Congeddu for useful initial information in MALDI-TOF MS technology; Dr. Enrico Sorisio, PharmaNess Sole Director, for his helpful suggestions; Professor Annalisa Marchi, Professor of Genetics at the Faculty of Biology and Pharmacy, University of Cagliari, for her valuable feedback and support.

\section{References}

[1] M. Ingelman-Sundberg, S. C. Sim, A. Gomez, and C. Rodriguez-Antona, "Influence of cytochrome $\mathrm{P} 450$ polymorphisms on drug therapies: pharmacogenetic, pharmacoepigenetic and clinical aspects," Pharmacology \& Therapeutics, vol. 116, no. 3, pp. 496-526, 2007.

[2] M. Ingelman-Sundberg, "Pharmacogenetics of cytochrome P450 and its applications in drug therapy: the past, present and future," Trends in Pharmacological Sciences, vol. 25, no. 4, pp. 193-200, 2004.

[3] J. Ragoussis, “Genotyping technologies for all," Drug Discovery Today: Technologies, vol. 3, no. 2, pp. 115-122, 2006.

[4] M. Falzoi, A. Mossa, E. Congeddu, L. Saba, and L. Pani, "Multiplex genotyping of CYP3A4, CYP3A5, CYP2C9 and CYP2C19 SNPs using MALDI-TOF mass spectrometry," Pharmacogenomics, vol. 11, no. 4, pp. 559-571, 2010.

[5] M. Falzoi, L. Pira, P. Lazzari, and L. Pani, "Analysis of CYP2D6 allele frequencies and identification of novel SNPs and sequence variations in Sardinians," ISRN Genetics, vol. 2013, Article ID 204560, 10 pages, 2013.

[6] D. van den Boom and M. Ehrich, "Discovery and identification of sequence polymorphisms and mutations with MALDI-TOF MS," Methods in Molecular Biology, vol. 366, pp. 287-306, 2007.

[7] Human Cytochrome P450 Allele Nomenclature Committee, http://www.cypalleles.ki.se/.

[8] NCBI Single Nucleotide Polymorphism dbSNP, http://www .ncbi.nlm.nih.gov/projects/SNP/.

[9] J. Sistonen, A. Sajantila, O. Lao, J. Corander, G. Barbujani, and S. Fuselli, "CYP2D6 worldwide genetic variation shows high frequency of altered activity variants and no continental structure," Pharmacogenetics and Genomics, vol. 17, no. 2, pp. 93-101, 2007.

[10] S. Fuselli, I. Dupanloup, E. Frigato et al., "Molecular diversity at the CYP2D6 locus in the Mediterranean region," European Journal of Human Genetics, vol. 12, no. 11, pp. 916-924, 2004.

[11] C. Sachse, J. Brockmöller, S. Bauer, and I. Roots, "Cytochrome P450 2D6 variants in a Caucasian population: allele frequencies and phenotypic consequences," American Journal of Human Genetics, vol. 60, no. 2, pp. 284-295, 1997.

[12] S. Raimundo, C. Toscano, K. Klein et al., "A novel intronic mutation, 2988G $>$ A, with high predictivity for impaired function of cytochrome P450 2D6 in white subjects," Clinical Pharmacology and Therapeutics, vol. 76, no. 2, pp. 128-138, 2004.
[13] L. D. Bradford, "CYP2D6 allele frequency in European Caucasians, Asians, Africans and their descendants," Pharmacogenomics, vol. 3, no. 2, pp. 229-243, 2002.

[14] D. Marez, M. Legrand, N. Sabbagh et al., "Polymorphism of the cytochrome P450 CYP2D6 gene in a European population: characterization of 48 mutations and 53 alleles, their frequencies and evolution," Pharmacogenetics, vol. 7, no. 3, pp. 193-202, 1997.

[15] M. Ingelman-Sundberg, "Implications of polymorphic cytochrome P450-dependent drug metabolism for drug development," Drug Metabolism and Disposition, vol. 29, no. 4, part 2, pp. 570-573, 2001.

[16] T. Shimada, F. Tsumura, H. Yamazaki, F. P. Guengerich, and K. Inoue, "Characterization of (+/-)-bufuralol hydroxylation activities in liver microsomes of Japanese and Caucasian subjects genotyped for CYP2D6," Pharmacogenetics, vol. 11, no. 2, pp. 143-156, 2001.

[17] ss469415642, CYP2D6 3176C>T, 2011, http://www.ncbi.nlm. nih.gov/projects/SNP/snp_ss.cgi?ss=469415642.

[18] ss469415643, CYP2D6 3948T>G, 2011, http://www.ncbi.nlm .nih.gov/projects/SNP/snp_ss.cgi?ss=469415643.

[19] I. Johansson, E. Lundqvist, M. L. Dahl, and M. IngelmanSundberg, "PCR-based genotyping for duplicated and deleted CYP2D6 genes," Pharmacogenetics, vol. 6, no. 4, pp. 351-355, 1996.

[20] QIAGEN LongRange PCR Handbook, 2008, http://www.qiagen .com/default.aspx.

[21] ss470263991, CYP2D6 -948C>A, 2011, http://www.ncbi.nlm .nih.gov/projects/SNP/snp_ss.cgi?ss=470263991.

[22] M. Falzoi, L. Pira, P. Lazzari, and L. Pani, Homo sapiens haplotype 1 cytochrome P450 2D6 variant (CYP2D6) gene, CYP2D6 ${ }^{*} 2 M$ allele, complete cds, GenBank: JN716373.1, 2011, http://www.ncbi.nlm.nih.gov/nuccore/JN716373.1.

[23] M. Falzoi, L. Pira, P. Lazzari, and L. Pani, Homo sapiens haplotype 2 cytochrome P450 2D6 variant (CYP2D6) gene, CYP2D6 ${ }^{*} 2 M$ allele, complete cdsGenBank: JN716374.1, 2011, http://www.ncbi.nlm.nih.gov/nuccore/JN716374.1.

[24] M. Falzoi, L. Pira, P. Lazzari, and L. Pani, Homo sapiens haplotype 3 cytochrome P450 2D6 variant (CYP2D6) gene, CYP2D6*2M/CYP2D6* 41 hybrid allele, complete cds, GenBank: JN716375.1, 2011, http://www.ncbi.nlm.nih.gov/ nuccore/JN716375.1.

[25] M. Falzoi, L. Pira, P. Lazzari, and L. Pani, Homo sapiens haplotype 4 cytochrome P450 2D6 variant (CYP2D6) gene, CYP2D6*2M/CYP2D6* 41 hybrid allele, complete cds, GenBank: JN716376.1, 2011, http://www.ncbi.nlm.nih.gov/ nuccore/JN716376.1.

[26] P. Oeth, M. Beaulieu, C. Park et al., Sequenom Application Note, April 2005.

[27] iPLEX Gold Application Guide, 2009, http://www.sequenom .com/Files/Genetic-Analysis-Files/iP-LEX-Application-PDFs/ iPLEX-Gold-Application-Guide-v2r1.

[28] Sequenom Assay Designer Suite, https://seqpwsl.sequenom .com/AssayDesignerSuite.html.

[29] Ensembl Genome Browser, http://www.ensembl.org/index .html. 

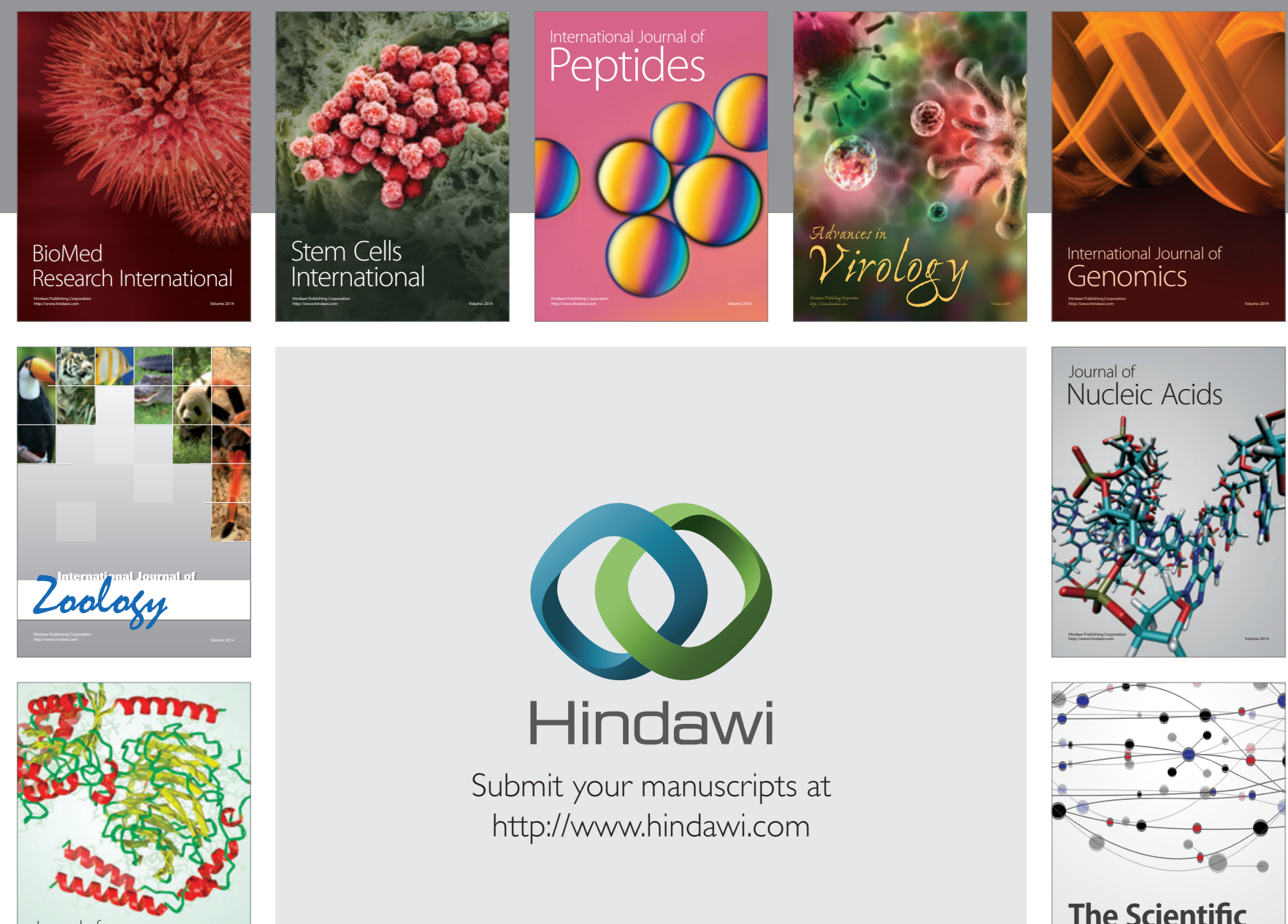

Submit your manuscripts at

http://www.hindawi.com

Journal of
Signal Transduction
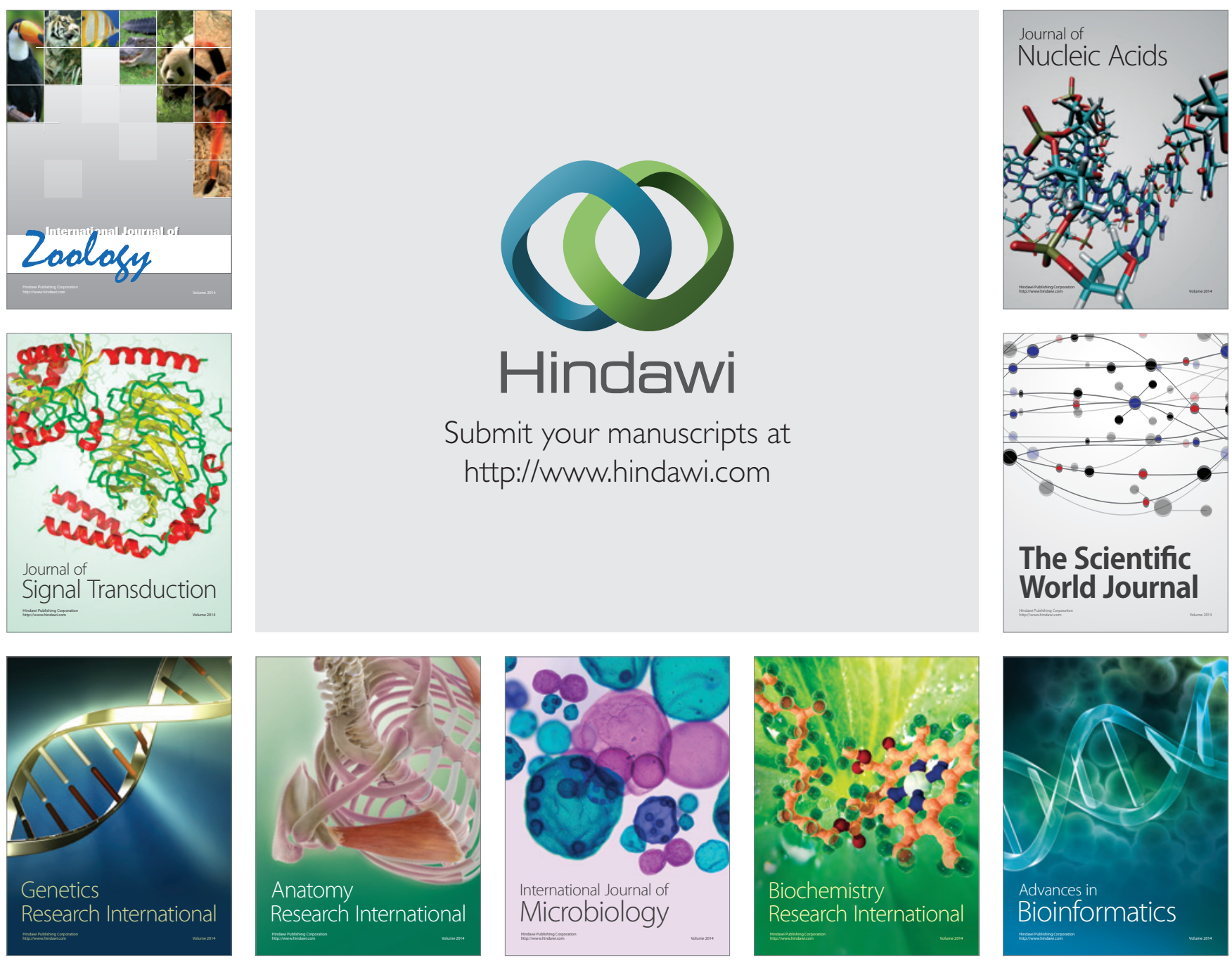

The Scientific World Journal
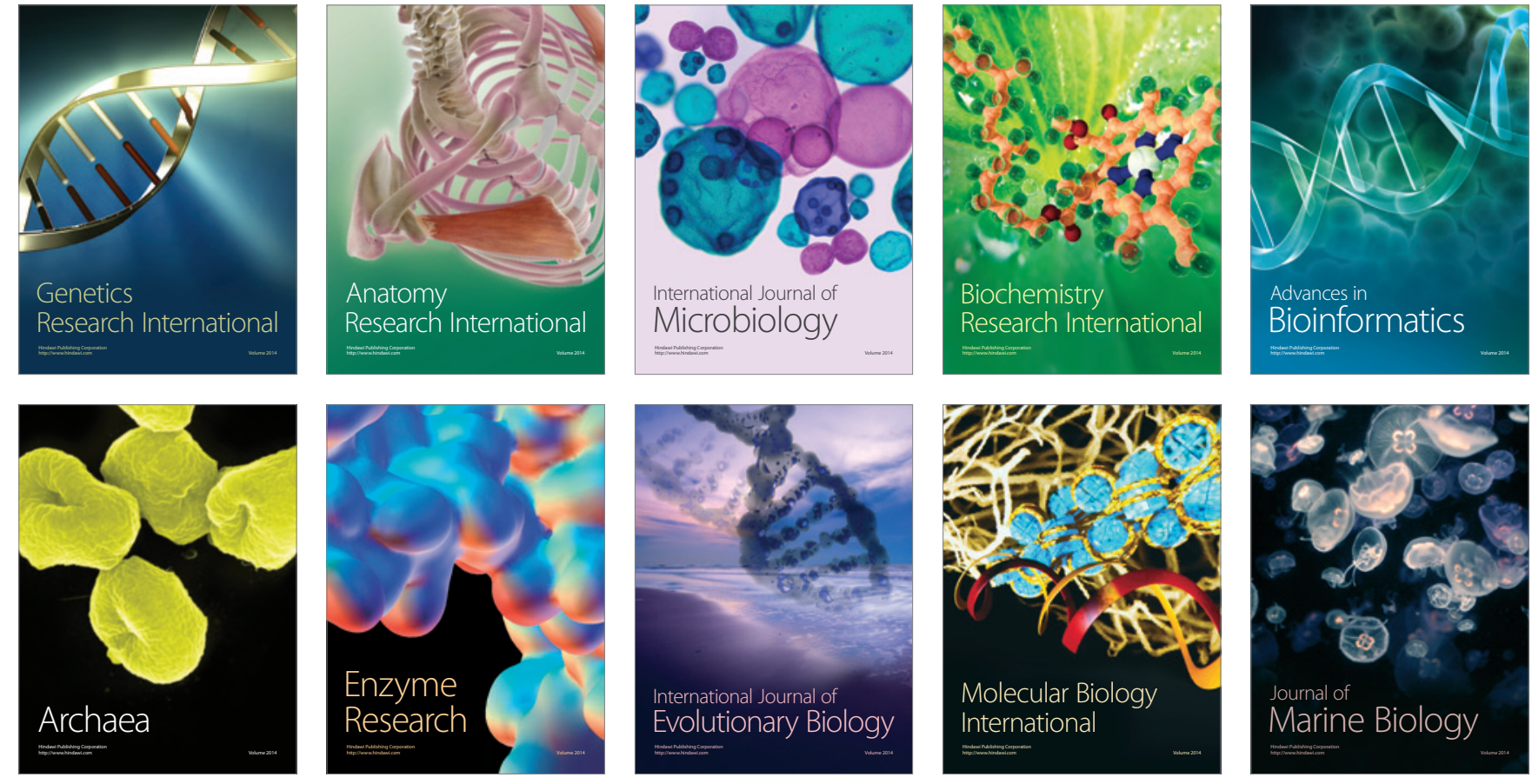